\title{
Empowering students to enhance education at their university
}

Jenny Marie, UCL

\begin{abstract}
This chapter analyses the development of a large institutional partnership scheme in order to demonstrate the importance of context and philosophy in shaping such schemes. All such schemes share a belief that students have valuable situated knowledge of the student experience and that they do not require further training or development to be able to offer something of value to educational practice. I argue that students may nevertheless still benefit from training; and that students are well placed to advocate for pedagogically sound practices. I highlight the important role that the institution can play as a partner in shaping projects through education strategy; and discuss the different challenges that face partnerships that are mainly student-led, staff-led or institutionled in my experience. I suggest that supervision forms a model for staff participating in partnership projects and call for further research into this and how we can encourage a contractual supervisory relationship. I also problemise the relationship between partnership work and the neoliberal agenda, suggesting that partnership can operate at macro and micro levels but neither is entirely in opposition to neoliberalism.
\end{abstract}

\section{Introduction}

This chapter considers the contexts, philosophies and practical realities that lie behind schemes that aim to empower students to enhance education within a Higher Education setting. The context of a scheme is important for understanding what is possible and the difference it is trying to make; the philosophy speaks more to the beliefs that lie behind the schemes and the values that it exhibits; while the practicalities show the limits within which the work occurs.

I use my experience of leading a large institutional partnership scheme at UCL for the past three years to explore these issues. UCL is a large research-intensive university, situated in the middle of London. It has approximately 40,000 students, just under half of whom are undergraduate, and approximately 80 departments. The scheme I lead has been highly successful; departments that received some form of support from it in 2015/16 had improvements in their National Student Survey (NSS) satisfaction rates that were statistically significantly higher than departments that did not engage with the scheme, both between 2015 and 2016 and from 2015 to 2017 and to 2018 (see also Marie and Azuma, 2018). The scheme has also supported the development of a whole range of resources and innovative practices. However, there have also been numerous challenges, which have led me to question the philosophical underpinnings of the scheme.

I discuss the limitations that I found with a 'students as change agents' model (Dunne et al., 2011) in terms of creating an environment conductive to the projects making a sustainable impact on education and as a mechanism for culture change across my university. As a result, I shifted the model behind the programme towards student/staff partnership (Cook-Sather et al., 2014, Healey et al., 2014). However, the reality lags behind: students who initiate projects often fail to properly engage with staff and students on staff projects are not always sufficiently empowered to contribute equally. Even where they appear to be, other commitments sometimes draw their attention away and staff have been frustrated by a lack of shared responsibility for seeing the project through. Partnership is not easy; it requires the negotiation of new roles in a context of participants simultaneously holding hierarchical ones (Cook-Sather, 2014).

At the same time, my institution is working towards an ideal of students being fully involved in all aspects of quality assurance and enhancement. As a result, we have invited students and departments with lower student satisfaction to work together to ensure there is sufficient student 
input on departmental enhancement plans and to implement parts of it in partnership. Despite a number of practical limitations (in particular time and money), these partnerships have been some of the most successful in terms of impact and conceptual changes amongst those taking part. This chapter explores how their impact has been ensured by their close link to departmental and institutional priorities and how students have overcome the institutional driver to make change that is meaningful for them.

\section{Developing a partnership scheme for funding enhancement projects}

The programme I lead, UCL ChangeMakers, was originally based on Exeter's 'students as change agents' scheme. The latter aims to give students the opportunity to make changes that are important to them: this may be to the environment, the local community or their educational experience. The changes are designed to make a lasting impact, through either making recommendations or having planned actions. For example, students persuaded the Business school to purchase 4000 voting sets as a result of their project (Kay et al., 2010).

The 'students as change agents' scheme originated in 2008, in a context of the UK government positioning students as consumers of their education (Browne, 2010). This was fiercely contended (and still is) by the National Union of Students (Wenstone, 2012) and by many working in universities. The 'students as change agents' scheme was clearly positioned in opposition to student consumerism, with students and staff having collective responsibility for the university (Dunne et al., 2011). Though the concept of 'students as partners' already existed, in the UK context of the late naughties it became positioned in opposition to the concept of 'students as consumers' (Neary and Winn, 2009). As I have argued elsewhere (Marie, 2018), this positioning is political rather than natural - partnership can serve the purposes of consumerism, as illustrated in section 'Consumerism?' below.

When UCL ChangeMakers took the 'students as change agents' model up in 2014, there were many examples of such initiatives across the country - the most notable being at Birmingham City and Winchester (Nygaard et al., 2013, Sims et al., 2016) - and these influenced the form of the scheme. For example, we originally used the idea of bursaries from the University of Winchester. The local context for our scheme also influenced its form. Based, as it is, in a department for academic development, it only funded projects that enhanced the student learning experience; rather than any aspect of the student experience as at Exeter. The Student Union recommended that we required the students to work with a staff partner from their department to give the projects legitimacy. The opportunity also existed for us to bring staff projects under the same scheme and to make it a condition that these were conducted in partnership with students. Philosophically, this came from a desire to create a single learning community at $\mathrm{UCL}$; whereby any member of the community could apply for the funding.

Bringing the staff projects under the scheme allowed us to adopt the aim of encouraging a culture of staff/student partnership for educational enhancement work, based on the idea that partnership work should produce results that better meet student needs because while staff have subject and pedagogic expertise, students better understand the student learning experience (Cook-Sather et al., 2014). In 2015/16, we drew the projects together under the scheme in a 'soft' way: we had funding ring-fenced for student-initiated projects and for staff-initiated projects, out of concern that the students would be out-competed for the funding by staff, who have more experience of writing grant bids. What we found was that (1) students wrote applications that were at least as good as those written by staff, particularly when we supported the application-writing process; and (2) that staff and students came together to write proposals and then did not know whether to submit their application as a student or staff project. The latter seemed to defeat our own purposes - we 
therefore abolished the distinction the following year and have found that the ratio of student and staff projects has been roughly equal in almost all funding rounds.

\section{The challenges of student-led and staff-led projects}

Despite our official abolition of the distinction between student and staff-initiated projects, it has remained far longer in our minds because there are significantly different challenges depending upon whether the project is student-led or staff-led, with truly collaborative projects being in the minority. An evaluation of the pilot year projects, which were all student-led revealed that students often did not work in partnership with their staff partners. Students thought that their staff partners were too busy; they found that they could run their projects alone; and communication between the students and staff was often difficult (Marie and McGowan, 2017). What we were finding at UCL, was that the 'students as change agents' model was not a model of partnership for enhancement projects: it was partnership at a higher, more conceptual level. This was recognised to some extent by the Exeter team, who wrote: "the way in which the scheme is organised does not require huge time commitments for academic and professional staff: hence they are more likely to engage and to maintain that engagement" (Kay et al., 2010).

At UCL, we found this was problematic for the projects making a lasting impact because students graduate, go on year abroad placements and so on. For the projects to make a lasting impact, they needed the buy-in of staff or the projects needed continuing support to enable a new set of students to take over and also gain recognition. At the end of 2015/16 matters came to a head; one of the projects we had funded that year was a highly successful project to organise a departmental conference in the Geography department (Thorogood et al., 2018). The project team approached us about gaining funding to run the project again the following year. My view, which was shared by the steering group, was that we could not fund such projects indefinitely or all our funding would eventually be used up supporting these projects. At the time we took a policy decision not to fund straight re-runs of projects; though we now offer continuation funding to support projects into their second year, with the explicit aims that they become embedded in (usually departmental) practice and they disseminate their work across the university. The decision led us to focus on the partnership element of the projects and to encourage students to see their project as aiming to change practice in the longer term, rather than to simply run a successful pilot or to make recommendations that are not taken up. The Geography conference itself did run again the following year despite failing to collect participant feedback, because it gained the support of the head of department and because it opened participation to college students and school teachers, thus enabling it to access outreach funding (Thorogood et al., 2018). This served as a lesson to the ChangeMakers team that we needed to emphasise the importance of evaluation, stakeholder engagement and creative thinking about how to engage stakeholders with required resources. The outcome of doing so has been that $18 \%$ of all projects (student and staff-initiated) in 2017-18 embedded change in the year of the project, up from 10\% in 2016-17 and a further $45 \%$ are estimated to have a good chance of embedding change within 2 years, up from 40\% in 2016-17.

The staff-led projects have not yet been systematically evaluated in the same way. However, there is always a fear about to what extent students are being empowered to work in partnership with staff and to what extent are they are being directed by them. My colleagues, Sandra and Abbie, tell me that students on staff-led projects are more likely to refer to their staff partner as their supervisor; suggesting that staff and students are falling back on this more familiar model of a relationship. Grant $(1999$, as cited in Deuchar, 2008) has argued that the doctoral supervision relationship is profoundly unequal in terms of power. However, supervisory relationships are not all the same. Taylor (2005) identifies four styles: 'laissez-faire' whereby the student is seen as capable of managing both their doctoral work and themselves; 'pastoral', whereby the student is seen as 
requiring personal support; 'directorial' whereby the supervisor helps the student to manage their project but does not provide personal support; and 'contractual' whereby the support given in these two dimensions is negotiated. The staff partners will focus on supporting the student to undertake the project - thus being more 'directorial'. However, the level of support may be open to negotiation, as per the 'contractual' style.

My own experience of acting as a staff partner on enhancement projects bears out the idea that the staff partner role can vary, while remaining supervisory, even within the same project. On one project, I set the brief as being to create student guides to assessment and feedback but was open to the students' ideas about the format they should take and how they would go about creating them. The students opted to run focus groups to find out what students would gain from learning, what they wanted to know and to gain quotes about good practice that they could include within the guides. I would never have gone about the project in this way: but it has worked. Up to this stage, my role had been to encourage and to motivate the project through a series of meetings to discuss progress. Where my fellow staff partners became more directive was when the guides were at draft stage and we requested that they sought staff and student feedback and conducted student usertesting. At this stage, the students could have refused but the power lay with the staff: we were the ones that would arrange the production and distribution of the guides and we were unlikely to do that without them passing through some quality assurance process. Our role changed during the project from supervisor to a gate-keeper for the project's lasting impact.

As Alison Cook-Sather (2014) has argued it is hard to adopt new roles while simultaneously holding onto our traditional hierarchical ones, as students or staff. One of the implicit assumptions in what has been written above is the support that we provide to the projects as a scheme. It has been fairly implicit because for us it has never been in question. Yet I have seen funding given to partnership projects with no support in place. Over the years we have developed this, such that all projects now have an opening meeting to ensure that they have a clear project plan, they have thought about how to embed this in practice and they have agreed how they will work together in partnership - in other words, they have started to form that contract.

\section{Forwarding education in line with strategy}

The 'students as change agents' model has one further difference from the one currently being pursued by UCL ChangeMakers. Dunne et al. (2011) explicitly position 'students as change agents' as going beyond partnership, which they state is usually institutionally driven, such that students make change meaningful and important to themselves.

In drawing the staff projects into UCL ChangeMakers, we also drew in some of the drivers behind these grants. Their purpose had been to forward UCL's research-based education strategy, the Connected Curriculum (Fung, 2017). Over time we realised that our decision-making about which projects to fund usually considered projects that would forward the education strategy but not the Connected Curriculum as equally valid; we therefore changed the funding criteria to forwarding UCL's Education or Doctoral Education strategy.

The reasoning for adopting strategic criteria for the grants was pragmatic: if you want to take over staff grants in order to encourage a culture of partnership for educational enhancement work, you inherit the drivers for those grants. Yet, the philosophy of this is significantly different from that of students making the changes that they care about. The concept of partnership is founded upon the idea that students have situated knowledge about the student experience (Cook-Sather et al., 2014, Haraway, 1988) and it questions concepts of patronage, whereby institutions know what is best for their students (and staff). However, while it brings into question that institutions know best, it does 
not deny that they have some relevant expertise to bring to this question. As Cook-Sather et al. (2014) state staff have pedagogic and subject expertise. This expertise will also be important in determining what educational changes will have the most impact. Institutional strategies go beyond this, considering the national and international context in which the institution sits, the institution's strengths, weaknesses and aims. Though some aspects are likely to be more pertinent to particular departments, the strategy adds another dimension of expertise.

Strategies exist to enable prioritisation of time, effort and funding. However, they need to exist outside of local contexts. For UCL ChangeMakers, students and staff put forward the projects that are important to them, based on their expertise in the student experience, the staff experience, subject-knowledge and/or pedagogic expertise. Our experience in running the projects (are they feasible, how likely are they to make a lasting impact, will they be run in partnership and so on) and strategy are layered over this to help us bring together all of this expertise to select projects that we believe are most likely to forward the student learning experience at UCL.

\section{Institutional-led change}

The projects described above have originated at grass roots level, whether from students or staff, despite being judged, in part, on institutional priorities. In 2015/16, I started to design a package of partnership work, which originated with the institution. At that time, UCL changed its method of annual monitoring to an Annual Student Experience Review (ASER), whereby departments were given a data set and were asked to evaluate their provision and create a developmental plan for the coming year. Departments with low levels of student satisfaction, as measured by the National Student Survey (NSS), were given additional support in the form of meetings with senior managers and were asked to undertake a project in partnership with students in the area of Assessment and Feedback. Assessment and Feedback was chosen due to this being the area of the NSS for which UCL gets its lowest student satisfaction ratings and thus improvement in this area is an institutional priority.

The rationale behind the projects was that by increasing student engagement with their department, student satisfaction levels should also rise. This hypothesis was based on the finding of Zhao and Kuh (2004) that increased student participation in a learning community increases both student engagement and student satisfaction. Though Zhao and Kuh only included students within their definition of a learning community, broadening its definition to include departmental staff was not thought likely to change the benefits to student satisfaction. However, there was also a danger that if departments did not engage with the process they could send the message to their students that they did not care about them or their views. In other words, while the process was designed to provide a structure for improving the engagement of staff and students with each other; if staff failed to engage, this process risked highlighting that.

The project that was carried out in departments was informed, in the first year, by a mixture of the institutional framing described above, pedagogic input, student experiences and the departmental view. Having recruited students to conduct the projects, they were provided with some pedagogic training in assessment and feedback, designed to give them ideas about potential projects. Thus in the training they were introduced to ideas such as guided marking (see example 3a in Cook-Sather et al., 2014) marker's commentaries (QMUL, 2011), feedback proformas and sheets for students to request a particular focus for the feedback they received (Bloxham and Campbell, 2010). The students then met with a departmental representative and I facilitated a meeting whereby they agreed a project between them. One of the things that surprised me (despite the example of the voting handsets at the University of Exeter described above) was how much more open staff were to ideas that came from their own students than they were to ideas from me as an academic 
developer. There is a concern that student partners should not be over-trained in pedagogy because it takes them away from their student perspective and positions them as having a deficit (Felten and Bauman, 2013). However, where students are allowed to judge pedagogic ideas from a student perspective, they can make the case for those they favour far more strongly than staff, even those whose expertise is in pedagogy.

Though this way of deciding the projects worked well, it was also very costly in terms of the support required from the UCL ChangeMakers team. There was also a further problem in that the students worked with their own department. While this meant that the students were completely familiar with the context of their work, it made it difficult for them to bring in good practice from elsewhere; the role was challenging for the students, who had to recommend enhancements to staff who taught and assessed them; and it created conflict with the role of student representatives, who were also expected to recommend educational changes. I therefore worked with the Student Union to devise a new role - that of the ASER facilitator, who is a student from a different department that meets with the department and student representatives to understand the departmental context before running a student focus group to better understand the student perspective. Coming from outside the department, they challenge the views of all parties and represent them back to each other, suggesting actions that can be taken to improve the student learning experience from their own experience in a different department. One of the things we are currently looking at is the possibility of the partnership project coming out of this work, whilst continuing to be conducted by staff and students from within the department.

\section{Consumerism?}

Partnership work at a local level at least, does not need to be in opposition to consumerism. Through undertaking projects students gain important employability skills, such as project management, managing resources and change management (Thorogood et al., 2018). The latter is the third of UCL ChangeMakers aims, and this aim can be thought of as serving consumerism because research has shown that well developed skills greatly enhance employability (Osmani et al., 2015).

Beyond this, the outcomes of the projects can improve student satisfaction levels. The departments that had an assessment and feedback project in 2015/16 saw an average increase in their NSS scores in this area of $5.2 \%$, compared to $0.9 \%$ for departments that had no such project (Marie and Azuma, 2018). When the normal UCL ChangeMakers projects are also taken into consideration, we see that departments with neither a ChangeMakers project at undergraduate level nor an Assessment and Feedback project saw a drop of $3.8 \%$ in their NSS overall satisfaction levels, compared to an increase of 3.5\% for departments that had either (or both) a UCL ChangeMakers project at undergraduate level and/or an Assessment and Feedback project.

The aim of raising satisfaction levels can be critiqued - there is a difference between satisfaction and learning and the two sometimes conflict. The UK's National Student Survey (NSS), which is used to measure satisfaction levels, originated as part of the apparatus of students becoming consumers (Crawford, 2012). It was intended to be a tool for students to select their university based on student satisfaction levels, which are made public. The concept of student consumerism has been critiqued on the many grounds: students cannot buy a degree; learning is an active process to which they must contribute - in other words they must be partners in their learning. Moreover, students are not sole experts in what is best for them: staff have the expertise in pedagogy and the subject, and standards are safe-guarded within the sector by external bodies such as the Quality Assurance Agency and professional bodies. Such arguments lie behind the rationale for partnership work. However, none of these arguments posit that it is a bad thing for students to get a good job on 
graduation or that students should not be satisfied with the education they receive, so long as satisfaction is seen within a broader context of learning.

There are many beneficiaries of higher education: the students themselves, the providers, employers and society. Students should have some rights and say, as per the consumerist model; so long as this is within a context of other stakeholders also having a say - in other words the consumerist model is okay so long as it represents the student voice as just one of the voices within a bigger frame of partnership.

\section{Conclusion}

Partnership schemes are products of their contexts. Each has its own aims and underlying philosophy, which will differ slightly from each other. What partnership work has in common is an underlying belief in situated knowledge and a philosophy of abundance rather than deficit. Students know things that staff cannot because they are not in the same situation; and students have knowledge and ideas to offer now - they do not have to wait until some future point when they are considered sufficiently formed. As a result of the abundance model, I have been cautious about training students in pedagogy - worried about moving them from their student perspective. Yet if we take the idea of situated knowledge seriously, students will retain this while gaining pedagogic knowledge. The work of the students negotiating the assessment and feedback projects above suggested that they can look at pedagogic ideas through a student lens and more powerfully argue for those that suit students with departmental staff than an academic developer can.

Most partnership work focuses on the relationship between staff and students. In this chapter, I've flagged another important partner that tends to be less considered: the institution, who I argue has expertise to offer in the form of understanding the institution's context and its strengthens and weaknesses. 'Students as change agents' was in part a reaction against the institution setting the agenda. I believe that, practitioners in the UK at least, have over-compensated for this. The context is such that the importance of allowing students to help shape the agenda is now sufficiently recognised that we can consider not only the role and expertise that staff bring to this, but also the institution.

Partnership work may be entirely collaborative, but in the majority of situations it is likely to be led by either students, staff or the institution. Each offers its own challenges - which in the case of UCL included sustaining impact, empowering students and institutional politics respectively. Further investigation is required to fully understand the different challenges that each faces. The staff-led projects at UCL suggests that, in a context of a lack of clarity about the relationship between staff and students, partners may be falling back onto a model that they are familiar with: that of supervision. More work is required to explore this fully, but if this is the case, we need to think about how to encourage the more contractual type of supervisory relationship that seems to be more in keeping with partnership work.

Partnership has been framed as being in opposition to consumerism. Yet consumerism has many facets to it. Partnership is in opposition to the idea that by paying fees students have no further responsibility for their own education. Yet, this can be interpreted in different ways. If partnership is considered at a macro level, whereby the student body and the university are both seen as responsible for enhancing the student learning environment - students could be considered to fulfil their responsibility via student representation, the giving of feedback and/or students as change agents. The first two are still considered in line with consumerism - as they could be done by giving customer feedback and leaving it to the institution to respond. At a micro level, partnership occurs when staff and students have joint responsibility for an aspect of education. Yet the outcomes of 
this are likely to be those sought within a consumerist model - better employment statistics and improved student satisfaction. If the debate over whether we want/work within a partnership or consumerist model is to move on, both partnership and consumerism need to be further unpicked.

\section{References}

BLOXHAM, S. \& CAMPBELL, L. 2010. Generating dialogue in assessment feedback: exploring the use of interactive cover sheets. Assessment \& Evaluation in Higher Education, 35, 291-300.

BROWNE, J. 2010. Securing a sustainable future for higher education: an independent review of higher education funding and student finance.

COOK-SATHER, A. 2014. Student-faculty partnership in explorations of pedagogical practice: a threshold concept in academic development. International Journal for Academic Development, 19, 186-198.

COOK-SATHER, A., BOVILL, C. \& FELTEN, P. 2014. Engaging students as partners in learning and teaching: A guide for faculty, John Wiley \& Sons.

CRAWFORD, K. 2012. Rethinking the student/teacher nexus: students as consultants on teaching in higher education. In: NEARY, M., STEVENSON, H. \& BELL, L. (eds.) Towards teaching in public: Reshaping the modern university.

DEUCHAR, R. 2008. Facilitator, director or critical friend?: Contradiction and congruence in doctoral supervision styles. Teaching in Higher Education, 13, 489-500.

DUNNE, E., ZANDSTRA, R., BROWN, T. \& NURSER, T. 2011. Students as change agents: New ways of engaging with learning and teaching in Higher Education.

FELTEN, P. \& BAUMAN, H.-D. 2013. Reframing diversity and student engagement: Lessons from deaf-gain. In: DUNNE, E. \& OWEN, D. (eds.) Student engagement handbook: Practice in higher education. Bingley: Emerald Group Publishing Ltd.

FUNG, D. 2017. A connected curriculum for higher education, UCLPress.

HARAWAY, D. 1988. Situated knowledges: The science question in feminism and the privilege of partial perspective. Feminist studies, 14, 575-599.

HEALEY, M., FLINT, A. \& HARRINGTON, K. 2014. Engagement through partnership: Students as partners in learning and teaching in higher education. Heslington.

KAY, J., DUNNE, E. \& HUTCHINSON, J. 2010. Rethinking the values of higher educationstudents as change agents?

MARIE, J. 2018. The relationship between research-based education and student-staff partnerships. In: TONG, V. C., STANDEN, A. \& SOTIRIOU, M. (eds.) Shaping Higher Education with Students: Ways to Connect Research and Teaching. UCL Press.

MARIE, J. \& AZUMA, F. 2018. Partnership support for departments with low student satisfaction. Student Engagement in Higher Education Journal, 2, 70-77.

MARIE, J. \& MCGOWAN, S. 2017. Moving towards sustainable outcomes in student partnerships: Partnership values in the pilot year. International Journal for Students as Partners, 1.

NEARY, M. \& WINN, J. 2009. The student as producer: reinventing the student experience in higher education. In: BELL, L., STEVENSON, H. \& NEARY, M. (eds.) The Future of Higher Education: Policy, Pedagogy and the Student Experience. London: Continuum.

NYGAARD, C., BRAND, S., BARTHOLOMEW, P. \& MILLARD, L. 2013. Student Engagement: Identity, Motivation and Community, Faringdon, Libri Publishing.

OSMANI, M., WEERAKKODY, V., HINDI, N. M., AL-ESMAIL, R., ELDABI, T., KAPOOR, K. \& IRANI, Z. 2015. Identifying the trends and impact of graduate 
attributes on employability: a literature review. Tertiary Education Management, 21, 367-379.

QMUL. 2011. Writing in Schools, Higher Education \& Employment Settings [Online]. Available:

http://www.thinkingwriting.qmul.ac.uk/wishees/collections/quinnipiac/microbiologyu ndergraduatereport/55529.html [Accessed 5 October 2018].

SIMS, S., KING, S., LOWE, T. \& EL-HAKIM, Y. 2016. Evaluating partnership and impact in the first year of the Winchester Student Fellows Scheme. The Journal of Educational Innovation, Partnership and Change, 2.

TAYLOR, S. 2005. A handbook for doctoral supervisors, London, Routledge Falmer.

THOROGOOD, J., AZUMA, F., COLLINS, C., PLYUSHTEVA, A. \& MARIE, J. 2018. Changemakers and change agents: encouraging students as researchers through Changemaker's programmes. Journal of Geography in Higher Education, 1-17.

WENSTONE, R. 2012. A manifesto for partnership. National Union of Students.

ZHAO, C.-M. \& KUH, G. D. 2004. Adding value: Learning communities and student engagement. Research in higher education, 45, 115-138. 